\title{
Importance of Pulmonary Hypertension Diagnosis
}

\author{
B. K.S. Sastry
}

Pulmonary Hypertension means increase in pulmonary artery mean pressure more than $25 \mathrm{~mm} \mathrm{Hg}$ and is associated with various disease conditions. It always worsens the prognosis of the underlying disease. World over there are many conditions which lead to $\mathrm{PH}$. The most common cause of PH is left heart disease. In India, compared to other parts of the world, $\mathrm{PH}$ associated with congenital heart disease and rheumatic heart disease continues to be important. At the same time due to demographic transition, $\mathrm{PH}$ due to diastolic heart failure of the left ventricle is fast becoming common. With improved efforts by way of education, $\mathrm{PH}$ due to shunt lesions called Eisenmenger syndrome can be prevented and chronic thrombo embolic $\mathrm{PH}$ can be cured in many patients. Idiopathic pulmonary artery hypertension (IPAH) in Group 1 disorders is a main cause of concern and it has particular poor prognosis.

This study is mainly aimed to evaluate the outcomes of PCI in diabetic patients comparing those who are non diabetics and to see if there is any significant difference in outcomes and complication between these two subgroups especially with reference to the gender.

Every year $5^{\text {th }}$ May is celebrated as World Pulmonary Hypertension (PH) day. It is the day commemorative of the death anniversary of the1st child who had PH due to toxic rapeseed oil and died 30 years ago. The purpose of celebrating this day is to raise awareness of this rare and fatal disease (IPAH) and high light the lives of the people living with this condition. There are about 25 million people suffering from this disease world over and till today there is no cure for this disease. The diagnosis is often missed and average time to diagnosis is still 2.8 years even in the developed western countries.

This being a rare disease, often many physicians do not even consider the diagnosis early stages and for long time patients are treated as asthma, seizures disorder and even psychogenic disease. Rarity of the disease combined with paucity of curative and affordable treatment makes it a medical challenge to many physicians.
The main purpose of celebrating this day is to draw global attention to this disease. Sensitized physicians consider the diagnosis as often as needed and decrease the chances of missed diagnosis. Early treatment would no doubt improve survival as well as quality of life for these patients. By organizing seminars and webinars on this day, physician education is sustained. I personally congratulate Dr. Jyotsna for taking lead in organizing such a webinar for the purpose of dissemination of knowledge to medical professionals.

Promotion and wide spread advertisement of this rare disease will ignite society's interest in this disease. Articles are published in vernacular media to educate the general public. This will help improve the understanding of the disease. An educated society can deal with the disease better. Participation of all stake holders would have impact on better health care delivery and better outcomes to the patients.

Patient meeting are held so that they can interact with each other and learn from each other's' experiences. Their confidence to deal with the disease increases. Such interaction will alter the attitude of both the patients as well as physicians and that would lead to treatment of the patient as a whole rather than some other ailment.

PH expert centers are identified and brought in to notice. Expert centers will definitely improve the outcomes of these patients while decreasing the costs of the management. Development of such expert centers would be conducive for research which is urgently needed for this disease. They can be the best interface between various stakeholders.

The day was officially endorsed by 22 patient associations, 10 rare and affiliated disease organizations, and 8 scientific societies. PH expert centers, hospitals, Physicians, physicians' associations, patients and their associations, patient advocacy groups and even governmental agencies may organize events to celebrate this day. 
In this issue there is an article by Dr. Basha, concentrating on the PAH secondary to the left heart diseases. Even though left heart disease is known common cause of $\mathrm{PAH}$, separate importance for management is not given in LV dysfunction patients. This article concentrates on this issue.

\section{REFERENCES:}

1. Marius M. Hoeper, MD; Harm Jan Bogaard, MD; Robin Condliffe, MD; Robert Frantz, MD; Dinesh Khanna, MD; Marcin Kurzyna, MD; David Langleben, MD; Alessandra Manes, MD; Toru Satoh, MD; Fernando Torres, MD; Martin R. Wilkins, MD; David B. Badesch, MD. Definitions and Diagnosis of Pulmonary Hypertension. J Am Coll Cardiol. 2013;62(25_S).
2. Hoeper MM. Definition, classification, and epidemiology of pulmonary arterial hypertension. Semin Respir Crit Care Med. 2009;30(4):369-75.

3. Jean-Luc Vachiéry, MD; Yochai Adir, MD, MHA; Joan Albert Barberà, MD, PhD; Hunter Champion, MD; John Gerard Coghlan, MD; Vincent Cottin, MD, PhD; Teresa De Marco, MD; Nazzareno Galiè, MD; Stefano Ghio, MD; J. Simon R. Gibbs, MD; Fernando Martinez, MD; Marc Semigran, MD; Gerald Simonneau, MD; Athol Wells, MD, MBSHB; Werner Seeger, MD, PhD*. Pulmonary Hypertension Due to Left Heart Diseases. J Am Coll Cardiol. 2013;62(25_S): 